\title{
A force-balance study of ice flow and basal conditions of Jutulstraumen, Antarctica
}

\author{
Øyvind Armand Høydal \\ Norsk Polarinstitutt, Majorstua, N-0301 Oslo, Norway
}

\begin{abstract}
Stresses and velocities at depth are calculated across Jutulstraumen, an ice stream in Dronning Maud Land, draining about $1 \%$ of the Antarctic ice sheet. The force-balance study is based on data from kinematic GPS measurements on three strain nets, each consisting of $3 \times 3$ stakes. The maximum measured velocity is $443 \mathrm{~m} \mathrm{a}^{-1}$ and the velocity variation over short distances is large compared with studied ice streams in West Antarctica. The surface topography together with the measured velocities across the profile indicate that the bottom topography has a great influence on the flow direction, even where the ice thickness is more than $2000 \mathrm{~m}$. The basal shear stresses are calculated as 180,227 and $146 \mathrm{kPa}$ in the three strain nets, while the corresponding driving stresses are 180,122 and $111 \mathrm{kPa}( \pm 5 \%)$. The heat produced by sliding and internal deformation is sufficient to keep the base at the pressure-melting point. The annual basal melting is estimated to be about $60 \mathrm{~mm}$. Investigations on the effect of temperature softening show that the flow parameter's influence on the effective strain rate is more important than the flow parameter's direct softening in the flow low alone. The mass flow calculated by the force-balance method is between 87 and $96 \%$ of pure plug flow and total discharge is calculated to be $13.3 \pm 10 \mathrm{~km}^{3} \mathrm{a}^{-1}$.
\end{abstract}

\section{INTRODUCTION}

Jutulstraumen, an ice stream in Dronning Maud Land (Fig. 1), is fed by an approximately $124000 \mathrm{~km}^{2}$ catchment basin, about $1 \%$ of the Antarctic ice sheet (Van Autenboer and Decleir, 1978). Jutulstraumen flows into Fimbulisen, where it protrudes as a floating ice tongue, named Trolltunga. This ice tongue has retreated considerably after a major calving event in 1967, when an iceberg approximately $100 \mathrm{~km}$ long and $50 \mathrm{~km}$ wide broke off (Vinje, 1977).

Previous studies of the mass balance of Jutulstraumen did not include its entire discharge. Gjessing (1972) collected gravity and velocity measurements between Jutulrora and northern Nashornkalven (also investigated in the present study; profile 1 in Fig. 1). Decleir and Van Autenboer (1982) recalculated the bottom topography from Gjessing's (1972) gravity measurements and estimated the discharge through this profile as $12.5 \mathrm{~km}^{3} \mathrm{a}^{-1}$, assuming plug flow. On the basis of this estimate, Bentley and Giovinetto (1991) calculated that accumulation exceeds outflow by $50 \%$. However, a large part of the Jutulstraumen accumulation area drains through Viddalen, between Nashornet and Istind (profile 2 in Fig. 1). No velocity data were available for the section across the outer part of Viddalen and the outflow there has so far been neglected. Satellite images indicate that as much as one-third of the ice mass in Jutulstraumen may flow through Viddalen. The outflow cross-sectional area in this study is based on the depth profiles of Decleir and Van Autenboer (1982) (Table 1).
The field work of this project was carried out during the Norwegian Antarctic Research Expedition 1992-93 (NARE 92-93) (Høydal, in press), in co-operation with Melvold and Hagen (in press). It has two objectives: (1) To clarify the mass balance of Jutulstraumen, and (2) to investigate the dynamics and the variation in the stress fields of this type of ice stream. Jutulstraumen is bounded by bedrock like alpine glaciers and therefore should differ in behaviour from the more comprehensively studied ice streams of West Antarctica.

The surface-velocity profiles consisted of 42 stakes across Jutulstraumen (Fig. 2). Twenty-seven of the stakes were arranged in $3 \times 3$ rectangular strain nets (Fig. 2). The stakes were surveyed using the Global Positioning System (GPS).

The strain-rate measurements from the three strain nets are used to calculate deformations, stresses and velocities at depth.

\section{MEASUREMENTS AND DATA ANALYSIS}

The relative positions of profile stakes were surveyed using phase-tracking kinematic GPS techniques (Eiken, in press). Three (WGS 84) GPS receivers were used for each survey. Two receiver antennas were mounted on fixed stakes at each end of the profile and continually recorded GPS signals. The third, roving, receiver and antenna was mounted on a sledge, towed by a snowmobile. The snowmobile drove along the profile, 


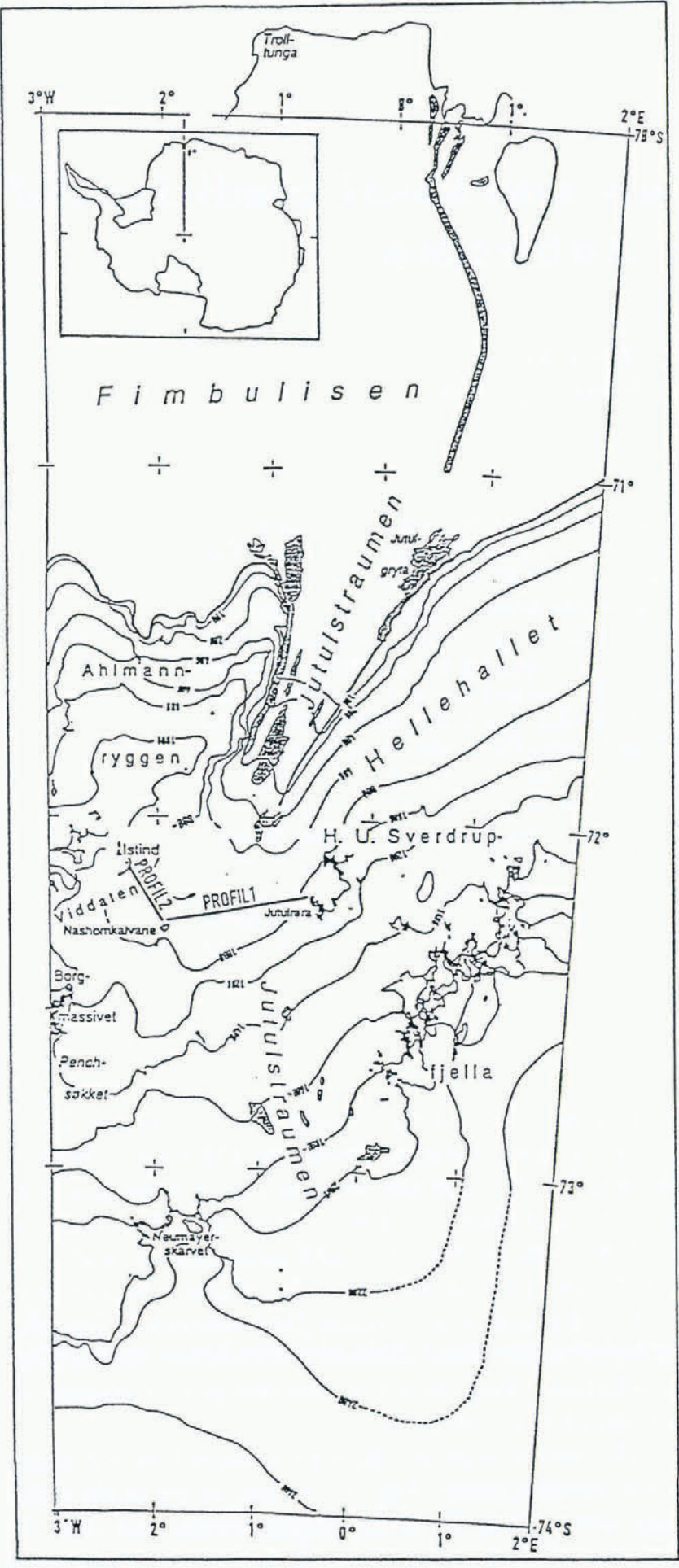

Fig. 1. Jutulstraumen at the zero meridian in Dronning Maud Land (map from Norsk Polarinstitutt).

making short stops at each stake and placing the antenna on the top of each stake. At each end of the profile, the roving antenna was interchanged with the fixed antenna. Relative positions of the stakes were computed using signals recorded by all three GPS receivers and Ashtech XII GPPS post-processing software.

The profiles were surveyed twice. The interval between each survey was $14 \mathrm{~d}$. The computed surface velocities are plotted in Figure 2 and velocities are listed in Table 1. These velocities are in good agreement with those measured by Gjessing (1972).
Stake-positioning errors (standard deviation) from the GPS measurements and processing are $0.05-0.06 \mathrm{~m}$ for net 1 and $0.02-0.03 \mathrm{~m}$ for nets 2 and $3.0 .005 \mathrm{~m}$ error on the stake positions results in about $0.1 \%$ error in the velocity for the slowest part of the ice stream. The maximum strain-rate error is $0.2 \times 10^{-3} \mathrm{a}^{-1}$ or about $10 \%$ of the values for net 1 given in Table 2 . The stresses are proportional to the strain rates and will contain the same error as the strain rates. The true errors in the strain rates at the nodes in Table 2 are considered to be smaller, because they are based on averages from four stakes and are more accurate positions for the stakes in nets 2 and 3. The standard deviation for the vertical positioning is larger than for the horizontal positioning. The maximum is $0.25 \mathrm{~m}$ and may result in a $5 \%$ error in the shear stresses for net 2, where the surface slope is smallest.

Force-balance calculations require four sets of strain rates and the surface slope for each $3 \times 3$ strain net. Surface slope is computed from relative elevations of the outermost stakes. Measured velocities are transformed into surface-parallel components and gridded to a regular $1 \mathrm{~km}$ grid using linear interpolations. The coordinate system is Cartesian with the $x$ axis eastward along the profile, the $y$ axis pointing northward and the $z$ axis positive upward normal to the local snow surface. Figure 3 illustrates the local coordinate system used in each strain net. Strain rates are computed in each quarter of a strain net, bounded by four stakes. The average normal strain rates from two sides are $\dot{\epsilon}_{x x}$ and $\dot{\epsilon}_{y y}$, while $\dot{\epsilon}_{x y}$ is an average from all four sides. All three quantities apply to the geometric centre of the square. This point is a node and a net consisting of $3 \times 3$ stakes gives four nodes. The values from these four nodes, together with the centre velocities and the surface slopes, are used in the model to compute stresses at the centre point of each strain net.

\section{FORCE-BALANCE THEORY}

Two simplifications are made to the well-established force-balance method of Van der Veen and Whillans (1989a). First, a Cartesian coordinate system is defined with the $z$ axis perpendicular to the snow surface. In this paper, planes parallel to the $z$ axis are called vertical. Next, a simplifying assumption regarding the hydrostatic pressure is made. The changes are described below.

For an element with density $\rho$ and sides $\partial x, \partial y$ and $\partial z$ parallel to the coordinate axes, the stress-balance equations are:

$$
\begin{aligned}
\partial \sigma_{x x} / \partial x+\partial \sigma_{x y} / \partial y+\partial \sigma_{x z} / \partial z & =-\rho g_{x} \\
\partial \sigma_{x y} / \partial x+\partial \sigma_{y y} / \partial y+\partial \sigma_{y z} / \partial z & =-\rho g_{y} \\
\partial \sigma_{x z} / \partial x+\partial \sigma_{y z} / \partial y+\partial \sigma_{z z} / \partial z & =-\rho g_{z}
\end{aligned}
$$

where $\sigma_{x x}, \sigma_{y y}, \sigma_{z z}$ are normal stresses, $\sigma_{x y}, \sigma_{x z}, \sigma_{y z}$ are shear stresses and $g_{x}, g_{y}, g_{z}$ are components of gravity in the $x, y$ and $z$ directions.

Stress-deviator components are obtained by subtracting the average normal pressure $\left(\left(\frac{1}{3}\right)\left(\sigma_{x x}+\sigma_{y y}+\sigma_{z z}\right)\right)$ from the normal stresses. The shear-stress components remain unchanged. 
Hoydal: Force-balance study of ice flow and basal conditions of futulstraumen, Antarctica

Table 1. Absolute velocity, normal velocity and ice flux

\begin{tabular}{|c|c|c|c|c|c|c|c|}
\hline Stake No. ${ }^{*}$ & $\begin{array}{l}\text { Velocity } \\
\mathrm{m} \mathrm{a}^{-1}\end{array}$ & $\begin{array}{c}n \text { Velocity } \\
\mathrm{ma}^{-1}\end{array}$ & $\begin{array}{c}\text { Width } \\
\text { m }\end{array}$ & $\begin{array}{c}\text { Thickness } \\
\text { m }\end{array}$ & Factor $^{\dagger}$ & $\begin{array}{c}\text { Flux } \\
\mathrm{km}^{3} \mathrm{a}^{-1}\end{array}$ & $\begin{array}{l}\text { Total flux } \\
\mathrm{km}^{3} \mathrm{a}^{-1}\end{array}$ \\
\hline 1 & 124.62 & 118.98 & 2439.51 & 850 & 0.93 & 0.23 & \\
\hline 2 & 153.45 & 146.55 & 878.81 & 900 & 0.93 & 0.11 & \\
\hline 3 & 173.83 & 167.82 & 2559.82 & 950 & 0.93 & 0.38 & \\
\hline 4 & 288.05 & 272.21 & 4208.24 & 1700 & 0.91 & 1.77 & \\
\hline 5 & 394.68 & 354.65 & 2522.93 & 2400 & 0.87 & 1.87 & \\
\hline 6 & 413.20 & 367.78 & 874.80 & 2400 & 0.87 & 0.67 & \\
\hline 7 & 418.96 & 373.76 & 2575.64 & 2400 & 0.87 & 2.01 & \\
\hline 8 & 380.70 & 358.43 & 4314.69 & 1300 & 0.92 & 1.85 & \\
\hline 9 & 261.04 & 245.39 & 4344.31 & 700 & 0.96 & 0.72 & \\
\hline 10 & 180.26 & 165.47 & 2598.33 & 700 & 0.96 & 0.29 & \\
\hline 11 & 165.71 & 151.99 & 870.66 & 700 & 0.96 & 0.09 & \\
\hline 12 & 157.71 & 139.36 & 2621.52 & 700 & 0.96 & 0.25 & \\
\hline 13 & 92.80 & 82.04 & 4361.59 & 700 & 0.96 & 0.24 & \\
\hline 14 & 73.32 & 65.30 & 3970.26 & 700 & 0.96 & 0.17 & \\
\hline 15 & 51.84 & 50.78 & 2792.18 & 1000 & 0.93 & 0.13 & \\
\hline 36 & 3.66 & 3.30 & 3000.00 & 500 & 0.99 & 0.00 & 10.78 \\
\hline 37 & 0.88 & 0.88 & 1329.44 & 500 & 0.99 & 0.00 & \\
\hline 38 & 136.60 & 87.10 & 3088.96 & 1200 & 0.92 & 0.30 & \\
\hline 39 & 182.19 & 124.32 & 3510.52 & 2200 & 0.87 & 0.84 & \\
\hline 40 & 179.17 & 142.67 & 3508.09 & 1900 & 0.90 & 0.86 & \\
\hline 41 & 70.31 & 67.18 & 3524.80 & 1400 & 0.91 & 0.30 & \\
\hline \multirow[t]{2}{*}{42} & 33.39 & 32.68 & 2267.71 & 800 & 0.95 & 0.06 & 2.35 \\
\hline & & & & & & Total Flux & 13.13 \\
\hline
\end{tabular}

Other stakes (velocity, $\mathrm{m} \mathrm{a}^{-1}$ )

$\begin{array}{lrrr}16 & 157.12 & 27 & 406.77 \\ 17 & 170.87 & 28 & 442.96 \\ 18 & 178.39 & 29 & 373.26 \\ 19 & 181.45 & 30 & 157.55 \\ 20 & 168.16 & 31 & 163.33 \\ 21 & 154.29 & 32 & 138.31 \\ 22 & 285.79 & 33 & 103.18 \\ 23 & 441.52 & 34 & 131.67 \\ 24 & 406.94 & 35 & 160.10 \\ 25 & 406.46 & 36 & 3.66 \\ 26 & 389.07 & & \end{array}$

* Stake numbers 1-36 are from northern Nashornkaalven to Jutulrøra. Stake numbers 37-42 are from northern Nashornkalven to Istind.

† Computed shape factor between computed mass flow and block flow.

By assuming the average normal stress to be constant along planes parallel to the surface, a good approximation to the stress-balance equations is achieved by replacing the derivatives of the normal stresses directly with the derivatives of the deviator-stress components:

$$
\begin{aligned}
& \partial \sigma_{x z}^{\prime} / \partial z=-\rho g_{x}-\left(\partial \sigma_{x x}^{\prime} / \partial x+\partial \sigma_{x y}^{\prime} / \partial y\right) \\
& \partial \sigma_{y z}^{\prime} / \partial z=-\rho g_{y}-\left(\partial \sigma_{y y}^{\prime} / \partial y+\partial \sigma_{x y}^{\prime} / \partial x\right)
\end{aligned}
$$

where $\sigma_{i j}^{\prime}, i, j=x, y, z$ are deviator-stress components.

Stresses are linked to strain rates $(\dot{\epsilon})$ through their deviator components $\left(\sigma^{\prime}\right)$ in the generalized flow law:

$$
\sigma_{i j}^{\prime}=A^{-1 / n} \dot{\epsilon}_{\mathrm{e}}^{(1 / n)-1} \dot{\epsilon}_{i j}
$$

where $A$ is the flow parameter among other features dependent on temperature. $n$ is an empirical derived constant, here taken to be equal to 3 (Paterson, 1981).

The effective strain rate $\left(\dot{\epsilon}_{\mathrm{e}}\right)$ is defined as:

$\dot{\epsilon}_{\mathrm{e}}{ }^{2}=\frac{1}{2} \dot{\epsilon}_{i j}{ }^{2} \dot{\epsilon}_{i j}{ }^{2}=\frac{1}{2}\left(\dot{\epsilon}_{x x}{ }^{2}+\dot{\epsilon}_{y y}{ }^{2}+\dot{\epsilon}_{z z}{ }^{2}\right)+\dot{\epsilon}_{x y}{ }^{2}+\dot{\epsilon}_{x z}{ }^{2}+\dot{\epsilon}_{y z}{ }^{2}$. 


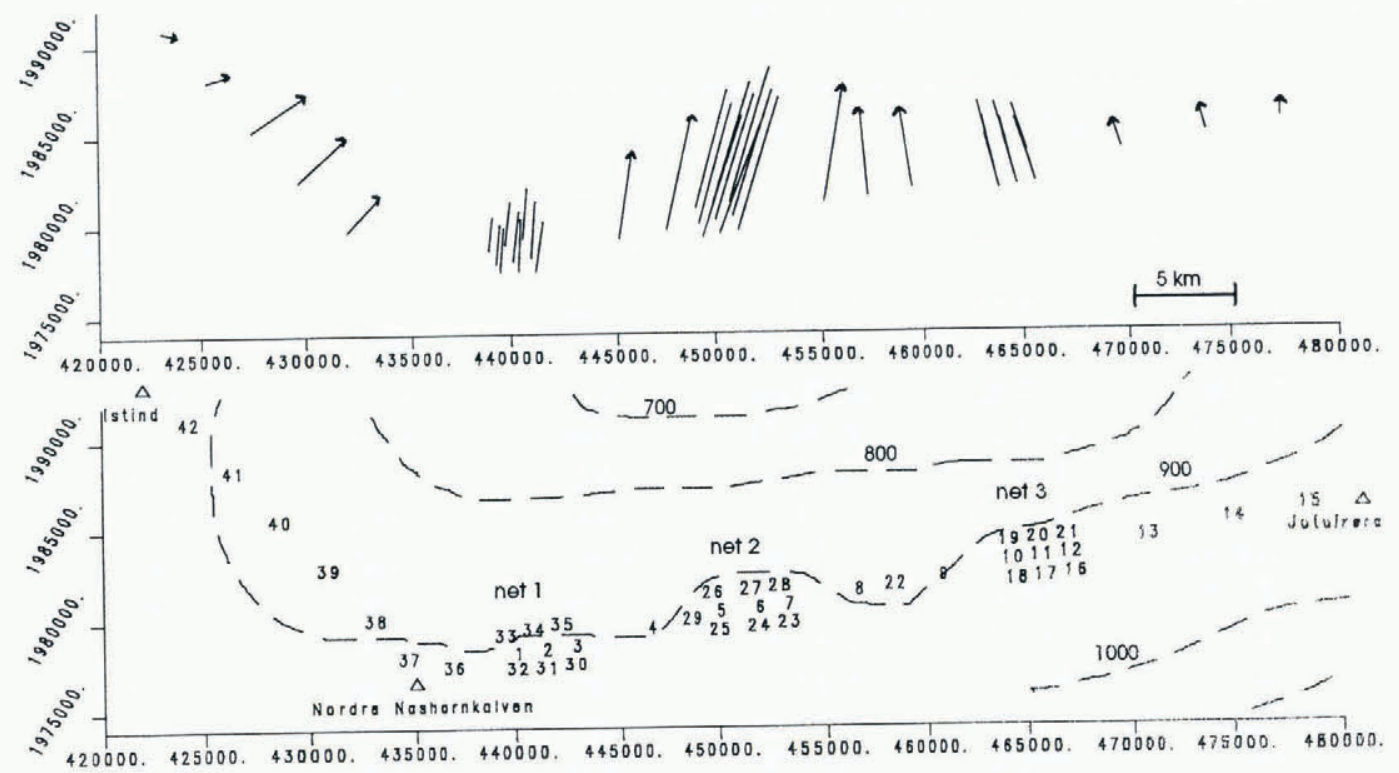

Fig. 2. Upper part: relative horizontal movements of the stakes. The longest line represents $443 \mathrm{ma}^{-1}$. Lower part: relative position of each stake and elevation contours. The numbers refer to stake and velocity data in Table 1.

In the field, velocity is measured at discrete locations. Horizontal strain rates at the surface are:

$$
\begin{aligned}
\dot{\epsilon}_{x y} & =\frac{1}{2}\left[\partial u_{y} / \partial x+\partial u_{x} / \partial y\right] \\
\dot{\epsilon}_{x x} & =\partial u_{x} / \partial x \\
\dot{\epsilon}_{y y} & =\partial u_{y} / \partial y .
\end{aligned}
$$

Assuming no vertical shear (e.g. $\left(\partial u_{z}\right) /(\partial x)=0$ and $\left.\left(\partial u_{z}\right) /(\partial y)=0\right)$, horizontal strain rates below the surface are computed using:

$$
\dot{\epsilon}_{x z}=\frac{1}{2} \partial u_{x} / \partial z \text { and } \dot{\epsilon}_{y z}=\frac{1}{2} \partial u_{y} / \partial z .
$$

The strain nets measured on Jutulstraumen were restricted to $3 \times 3$ arrays of stakes. This means that just one derivative of each surface-stress component can be calculated for each net. Instead of introducing additional points outside the measured area to provide lateral boundary conditions at depth (as in Van der Veen, 1989), the strain rates measured at the surface are kept constant with depth. This is believed to be the best assumption. There can never be any physical control of the boundary conditions at the margins of a strain net. Keeping the surface strain rates constant leads to decreasing longitudinal deviator stresses at depth

Table 2. Surface strain rates $\left(a^{-1}\right)$ and stresses $(k P a)$

Node

$\begin{array}{cc} & \text { Surface strain rates } \\ \dot{\epsilon}_{x x} & \dot{\epsilon}_{y y} \\ \mathrm{a}^{-1} & \mathrm{a}^{-1}\end{array}$

Net 1

1

2

3

4

Mean

$3.71 \mathrm{e}^{-03}$
$9.88 \mathrm{e}^{-03}$
$3.01 \mathrm{e}^{-03}$
$1.08 \mathrm{e}^{-02}$
$6.85 \mathrm{e}^{-03}$

$-6.52 \mathrm{e}^{-03}$
$-1.18 \mathrm{e}^{-02}$
$-2.93 \mathrm{e}^{-02}$
$-4.62 \mathrm{e}^{-03}$
$-1.31 \mathrm{e}^{-02}$

$1.61 \mathrm{e}^{-02}$
$1.51 \mathrm{e}^{-02}$
$2.10 \mathrm{e}^{-02}$
$-2.61 \mathrm{e}^{-03}$
$1.24 \mathrm{e}^{-02}$

$\dot{\epsilon}_{x y}$

$\mathrm{a}^{-1}$

$\sigma_{x x}^{\prime}$
$\mathrm{kPa}$

Surface stresses

$\begin{array}{ll}\sigma_{y y}^{\prime} & \sigma_{x y}^{\prime} \\ \mathrm{kPa} & \mathrm{kPa}\end{array}$

Net 2

$\begin{array}{lr}1 & 9.36 \mathrm{e}^{-03} \\ 2 & 1.81 \mathrm{e}^{-02} \\ 3 & 1.44 \mathrm{e}^{-02} \\ 4 & -3.34 \mathrm{e}^{-03} \\ \text { Mean } & 9.63 \mathrm{e}^{-03}\end{array}$

$$
\begin{array}{r}
1.45 \mathrm{e}^{-02} \\
-3.62 \mathrm{e}^{-03} \\
2.38 \mathrm{e}^{-03} \\
-2.94 \mathrm{e}^{-03} \\
2.58 \mathrm{e}^{-03}
\end{array}
$$

$1.66 \mathrm{e}^{-02}$
$3.14 \mathrm{e}^{-03}$
$-1.21 \mathrm{e}^{-02}$
$8.84 \mathrm{e}^{-03}$
$4.12 \mathrm{e}^{-03}$

$-2.44 \mathrm{e}^{-05}$
$3.75 \mathrm{e}^{-03}$
$-1.61 \mathrm{e}^{-03}$
$-1.39 \mathrm{e}^{-03}$
$1.81 \mathrm{e}^{-04}$

$-7.38 \mathrm{e}^{-03}$

$-1.11 \mathrm{e}^{-02}$

$-4.20 \mathrm{e}^{-03}$

$-5.48 \mathrm{e}^{-03}$

$-7.04 e^{-03}$

\section{6}

89

18

150

73.25

$\begin{array}{cc}-62 & 154 \\ -106 & 136 \\ -174 & 124 \\ -64 & -36 \\ -101.5 & 94.5\end{array}$

$\begin{array}{ccc}66 & 103 & 118 \\ 174 & -35 & 30 \\ 125 & 20 & -105 \\ -44 & -39 & 118 \\ 80.25 & 12.25 & 40.25\end{array}$

$\begin{array}{rrr}-102 & 0 & -96 \\ -39 & 46 & -137 \\ -24 & -35 & -93 \\ -100 & -19 & -76 \\ -66 & -2 & -101\end{array}$



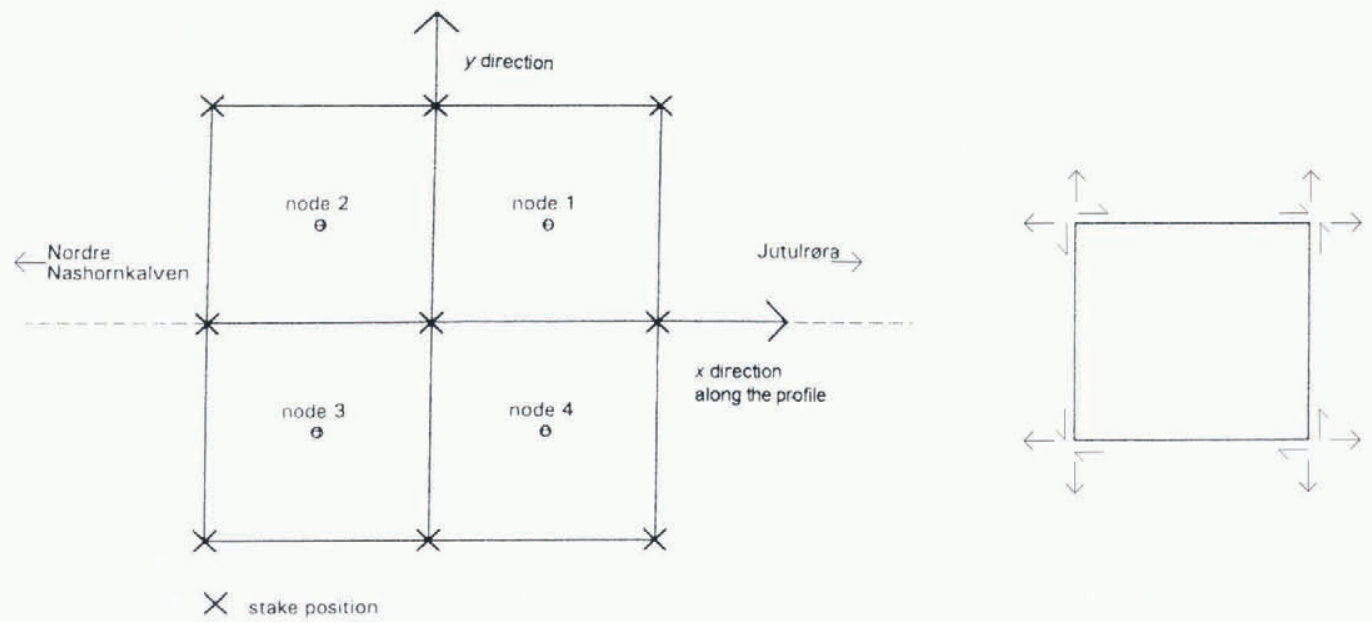

\begin{abstract}
Fig. 3. The lefthand figure illustrates the local coordinate system used at each strain net. The righthand figure illustrates the surface element spanned by the four nodes. The vertical arrows indicate a positive direction for $\sigma_{y y}^{\prime}$ at each node; horizontal arrows indicate a positive direction for $\sigma_{x x}^{\prime}$ and the half arrows indicate a positive direction at the corners of the shear stress $\sigma_{x y}^{\prime}$. All of these stresses act on surfaces parallel to the $z$ axis. These surfaces are close to vertical and $\sigma_{x y}^{\prime}$ is later called "vertical shear stress" in Figures 6, 7 and 8. $\sigma_{x x}^{\prime}$ and $\sigma_{y y}^{\prime}$ are the longitudinal deviator stresses.
\end{abstract}

because ice temperature, and thus softness, increases.

The effective strain rate $\left(\dot{\epsilon}_{\mathrm{e}}\right)$ is included in both Equations (4) and (5) and includes both $\dot{\epsilon}_{x z}$ and $\dot{\epsilon}_{y z}$. This coupling of $\dot{\epsilon}_{x z}$ and $\dot{\epsilon}_{y z}$ requires that Equations (4) and (5) are solved simultaneously. This is done by iterations where the effective strain rate is updated, representing the average effective strain rate in the integration layer.

Equations (4) and (5) are solved for $\partial \sigma_{x z}^{\prime} / \partial z$ and $\partial \sigma_{y z}^{\prime} / \partial z$ for thin layers parallel to the surface. The upperboundary conditions are a stress-free surface and surface velocity. Stresses and velocities at the lower surfaces can then be progressively calculated downward to the base.

\section{TEMPERATURE MODEL AND INPUT}

A model of temperature variation with depth is needed to estimate the values of the flow parameter $A$. Values for $A$ as a function of temperature have been tabulated in Paterson (1981). The temperature profile is estimated using a simple model from Robin (1955). The following assumptions are made:

1. Temperature distribution and ice geometry do not vary with time (i.e. steady state).

2. The basal temperature is below the melting point of ice.

3. The horizontal temperature gradient is negligible compared to the vertical temperature gradient. Thus, horizontal heat advection is negligible.

4. Heating from internal friction is mainly important in the lower layers and may be accounted for by increasing the geothermal heat flux, and similarly for heat generated by basal sliding.

Heating due to internal deformation, $\Phi$, depends mainly on horizontal shear stresses. However, this is not known a priori. An initial estimate is made using the flow law and assuming that $\sigma_{x z}=\rho g h \alpha$ :

$$
\Phi=\frac{2}{5} A(\rho g \alpha)^{n+1} h^{n+2}
$$

where $A$ is the flow rate in the flow law, $g$ is gravity, $h$ is ice thickness and $\alpha$ is surface slope. When force-balance calculations are carried out, a better estimate is found from:

$$
\Phi=2 \int_{0}^{z} \mathrm{e}_{x z} \sigma_{x z} \mathrm{~d} z .
$$

The heating from basal sliding is:

$$
\Phi_{\mathrm{b}}=\sigma_{\mathrm{b}} \nu_{\mathrm{b}}
$$

where $\sigma_{\mathrm{b}}$ is basal shear stress and $\nu_{\mathrm{b}}$ is basal sliding. This heating is initially set to zero.

The inputs required to compute a depth-temperature profile are accumulation, geothermal heat flux and surface temperature. Schytt (1958) measured accumulation at four locations along profile 1 in 1949 and 1950, with an average of $0.3 \mathrm{mw}$.eq. $\mathrm{a}^{-1}$ as a representative accumulation for the area.

The lower part of Jutulstraumen lies in a structural fault, Pencksökket (Penck Trough). It is believed that Pencksökket was formed during the Precambrian, so that heating associated with orogenesis should no longer influence heat flow. The geothermal heat flow is assumed to be $-54.6 \mathrm{~mW} \mathrm{~m}^{-2}$ or $-1.72 \times 10^{6} \mathrm{~J} \mathrm{~m}^{-2}$ year ${ }^{-1}$. This is a typical value (Sclater and others, 1980) for Precambrian shields.

The average annual surface temperature at the profiles is $-23^{\circ} \mathrm{C}$ and is found from temperature measurements made in shallow boreholes (Melvold and Hagen, in press). The average annual temperature is approximately $-23^{\circ} \mathrm{C}$. This agrees well with Schytt's (1958) estimates of average annual temperature of $-21.4^{\circ} \mathrm{C}$ at $770 \mathrm{~m}$ and $-24.7^{\circ} \mathrm{C}$ at $1280 \mathrm{~m}$ elevation. By interpolating Schytt's values, $-22.2^{\circ} \mathrm{C}$ is found at $900 \mathrm{~m}$ and $-22.9^{\circ} \mathrm{C}$ at $1000 \mathrm{~m}$ elevation. The profiles are all 


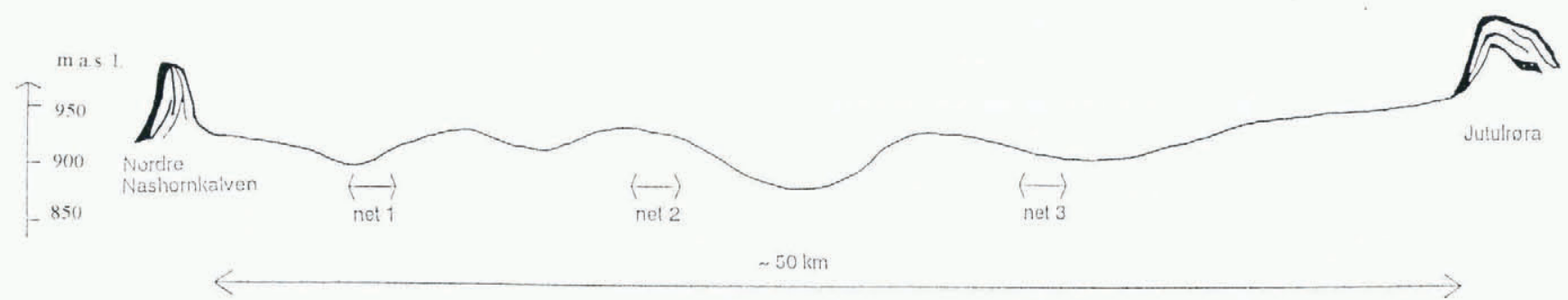

Fig. 4. The surface profile between . Nordre Nashornkalven and Jutulrora (profile 1).

located at about $900 \mathrm{~m}$ a.s.l. (Fig. 2).

The advection of ice from higher elevations undoubtedly causes a reversed temperature profile in the upper layers, as has been demonstrated in other sites (e.g. Van der Veen and Whillans, 1989b). The altitude of the upper accumulation area in Jutulstraumen is above $2500 \mathrm{~m}$ $(67 \%$ of the area is above $2500 \mathrm{~m})$ with an annual temperature between $-35^{\circ}$ and $-40^{\circ} \mathrm{C}$. A reversed temperature profile in the upper layers at Jutulstraumen is therefore to be expected.

This temperature model might seem too simplified for the present application. In an ice stream like Jutulstaumen, the basal temperature is possibly at the pressuremelting point, violating Robin's (1955) assumption (2). However, this solution must be valid when the temperature is close to the pressure-melting point, because a small change at the base will not significantly change the shape of the profile. The value of the flow parameter, $A$, is known at best within a factor of 5 (Hooke, 1981; Paterson and Budd, 1982). An error of $5^{\circ} \mathrm{C}$ in the temperature estimate will change the flow parameter by a factor of about 3. It is believed that the estimated temperature curves are accurate within $\pm 5^{\circ} \mathrm{C}$ and will not have much influence on the accuracy of the flow parameter.

To summarize: sliding and internal deformation produce heat that influences the temperature curve, so calculating ice temperature and deformation is a coupled problem. This is solved by successive calculations of the temperature and the deformation. The procedure is described below.

\section{RESULTS}

\section{Temperature}

Heating due to internal deformation is first estimated according to surface slope and a flow parameter representing $-20^{\circ} \mathrm{C}$ (Equation (13)). The initial heat flows, 109,82 and $57 \mathrm{~mW} \mathrm{~m}^{-2}$, are used to compute the basal temperatures that are $-11^{\circ},-6^{\circ}$ and $-16^{\circ} \mathrm{C}$ for nets 1,2 and 3 , respectively. The initial temperature profile is used in force-balance calculations to compute basal velocities and shear stresses. The cold, undeformable ice and large surface velocity result initially in large basal velocities. The theoretical heat generated by this "cold basal sliding" is an order of magnitude larger than the geothermal heat flow. The heat flow needed to keep the base at the pressure-melting point is just 182, 104 and $211 \mathrm{~mW} \mathrm{~m}^{-2}$ for nets 1,2 and 3, respectively. Van der Veen and Whillans (1989b), and the ensuing calculations, show that the ice temperature or variation in the flow parameter has a smaller influence on calculated horizontal shear stresses. Heat generated by internal deformation (Equation (14)) will then increasingly limit Equation (15) the closer to the base the differential movements occur. For all three nets, the heat generated by differential movements is more than necessary to keep the base at the pressure-melting point. The final temperature curves are shown in Figure 5.

The force-balance calculations result in internal heating (Equation (14)) + heating by sliding (Equation (15)) equal to:

$$
\begin{aligned}
570+320 & =890 \mathrm{~mW} \mathrm{~m}^{-2} \text { for net } 1, \\
2530+1250 & =3780 \mathrm{~mW} \mathrm{~m}^{-2} \text { for net } 2, \text { and } \\
230+570 & =800 \mathrm{~mW} \mathrm{~m}^{-2} \text { for net } 3 .
\end{aligned}
$$

The excess of heat results in basal melting. Taking only the heat produced by sliding into account, the basal melting is about $0.03,0.10$ and $0.05 \mathrm{~m}$ year $^{-1}$ for nets 1,2 and 3 , respectively, or $0.06{\mathrm{~m} y e a r^{-1}}$ as a mean. The difference in heat production at the three locations is mainly due to differences in the surface velocity. As long as the resulting sliding velocity produces more heat than is needed to keep the base at the pressure-melting point, the temperature curves in Figure 5a, d and $\mathrm{g}$ are expected to be a good approximation.

In order to test the dependence of the results on temperature, force balance is calculated assuming the ice is isothermal at $-25^{\circ} \mathrm{C}$.

\section{Effective strain rate}

The average effective strain rate, the average value from the four nodes at each vertical level is plotted in Figure 5. Two temperature profiles, one isothermal at $-25^{\circ} \mathrm{C}$, and the other computed as described above, are considered. In the isothermal case (Fig. 5c, f and i), the effective strain rates at the base are twice the surface values. When the estimated temperature profiles (Fig. 5a, d and g) are used, the changes in effective strain rate are much larger, with basal strain rates an order of magnitude larger than at the surface.

The large difference in effective strain rates between the isothermal and temperature-varying models is a result of the non-linearity of the flow law and the temperaturedependence of its flow parameter. In the isothermal case, the surface-measured stresses at the bed are reduced to $\sim 63 \%\left(2^{-\frac{2}{3}}\right)$ of the surface value (Figs 6,7 and 8 ). In the temperature-varying case, there is a feed-back effect from the effective strain rate, due to the increased flow 
Calculated temperature $\left({ }^{\circ} \mathrm{C}\right)$ Strain net No 1

a)

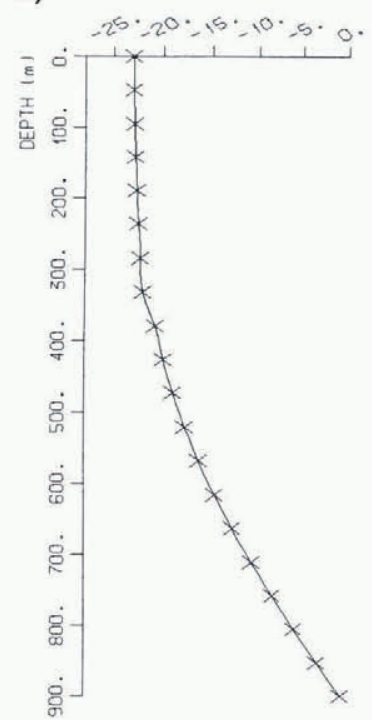

Strain net No 2

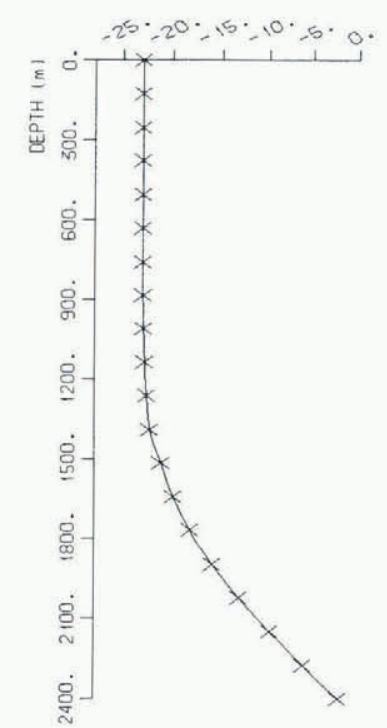

\section{Strain net No 3}

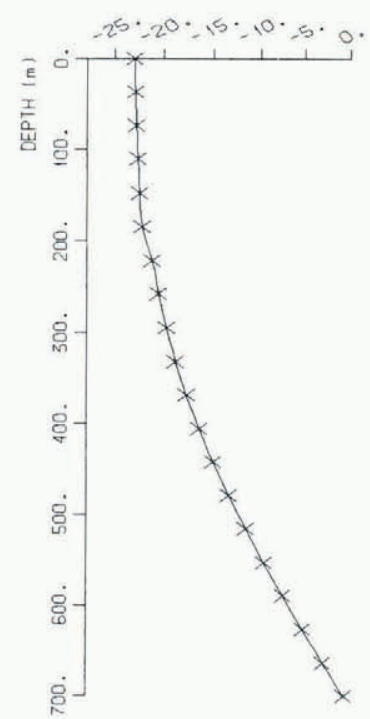

\section{Average effective strain rate}

b)

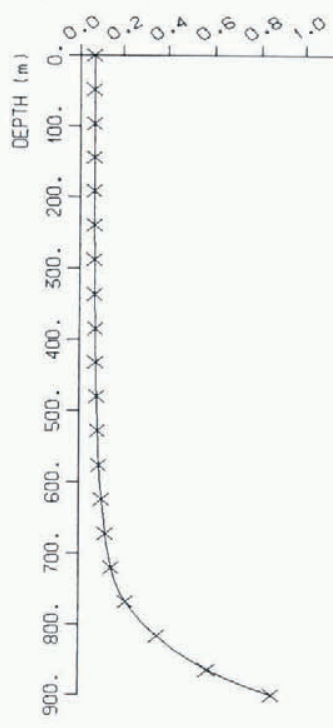

c)

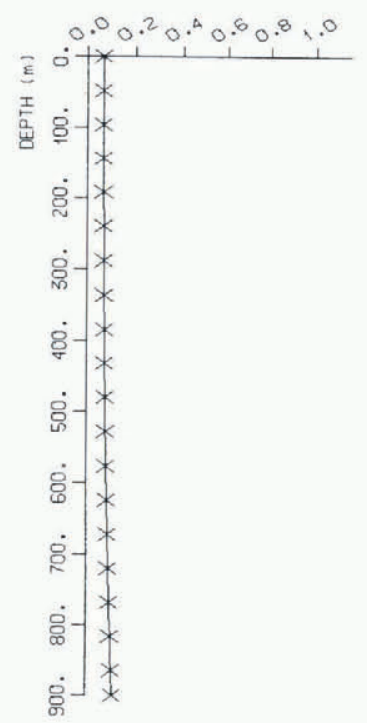

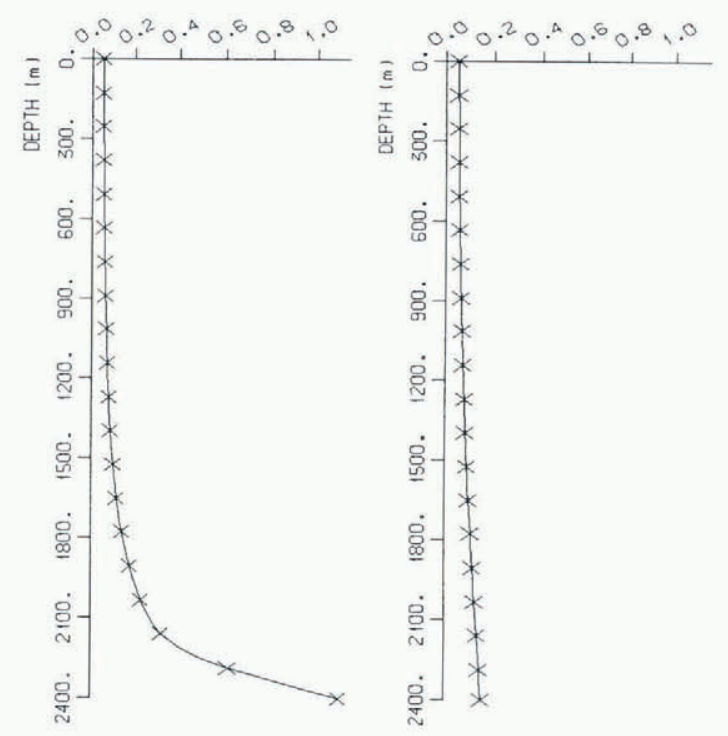

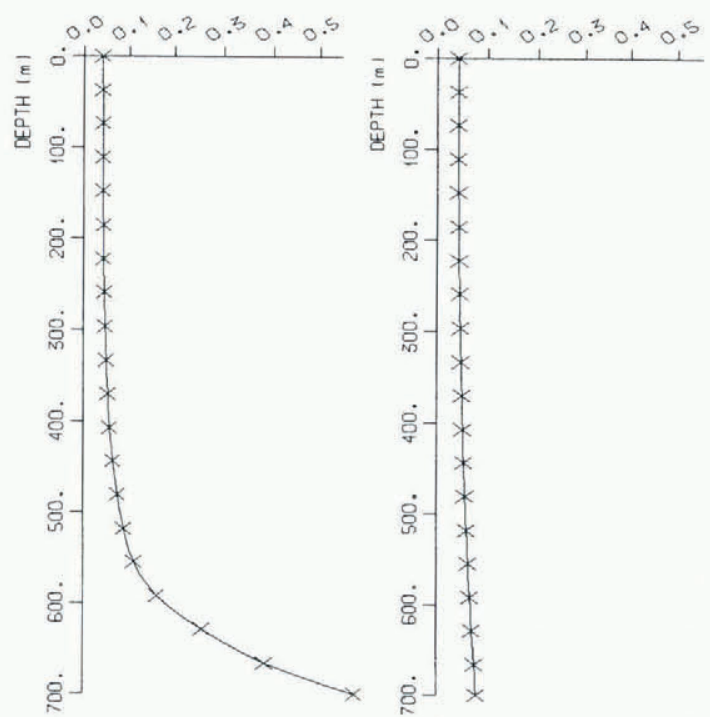

Fig. 5. Temperature curves for strain nets 1-3. a, calculated temperature; $b$, average effective strain rate: temperature calculated; $c$, average effective strain rate: isotherm. 


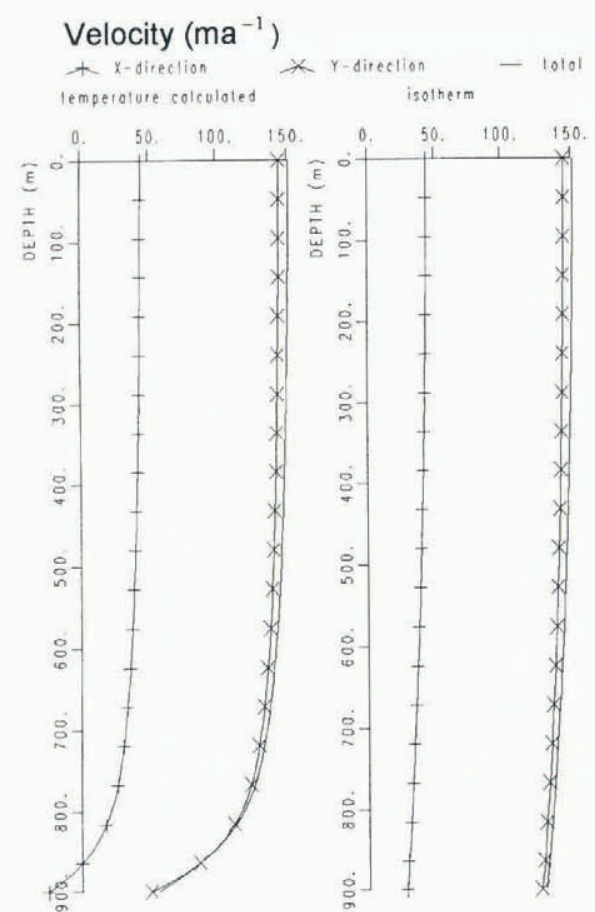

Average shear stress on vertical planes $(\mathrm{kPa})$
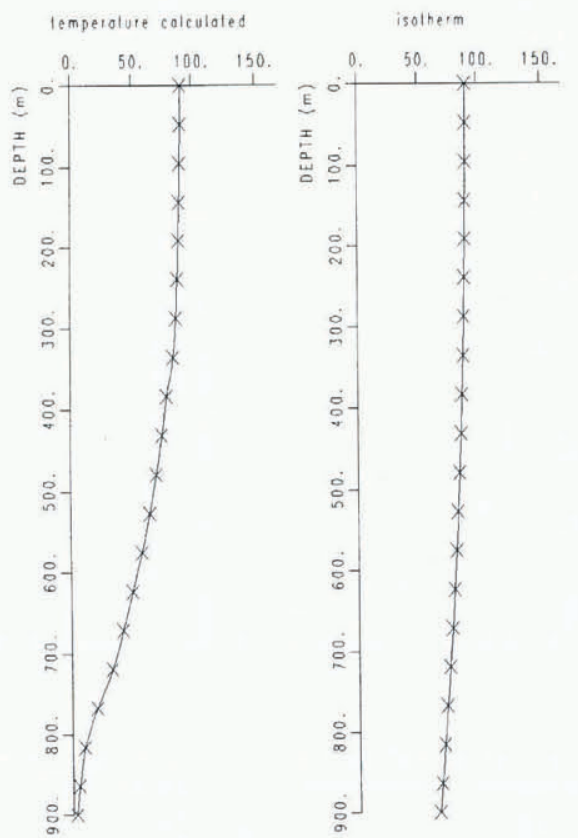

Average longitudinal deviator stresses $(\mathrm{kPa})$

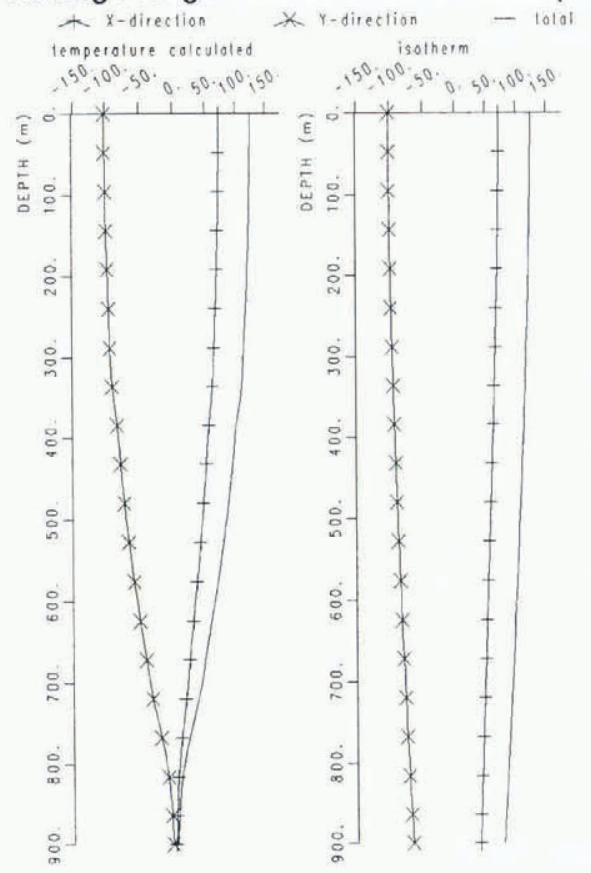

\section{Shear stresses on surface parallel planes $(\mathrm{kPa})$}
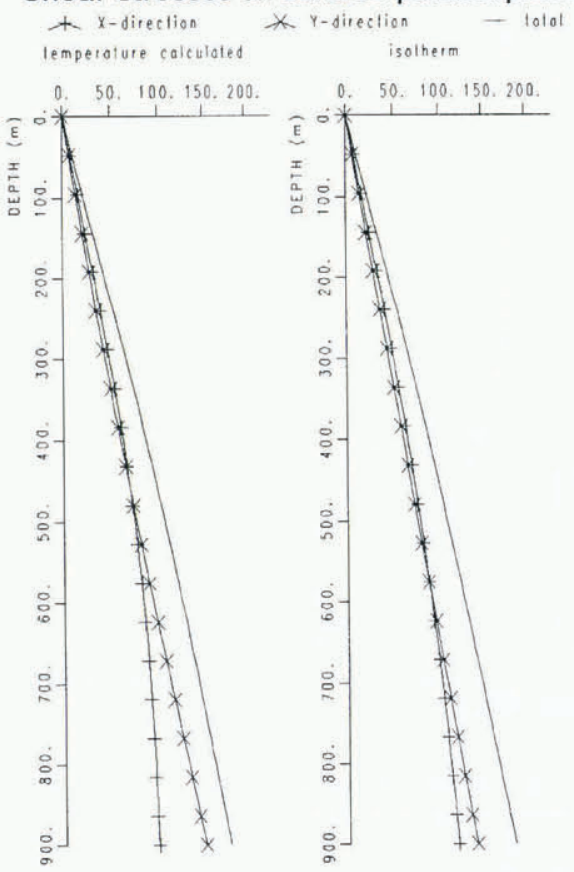

Fig. 6. Strain net No. 1. Velocities and stresses are calculated (1) by using the temperature profile in Figure 5 and (2) by assuming the ice temperature is constant and equal to $-25^{\circ} \mathrm{C}$.

parameter. The order-of-magnitude increase in effective strain rate at the bed decreases the measured surface stresses to $21 \%\left(0^{-\frac{2}{3}}\right)$ of the surface value. The change in the temperature from the surface to the bottom increases the flow parameter about 50 times. This reduces the deviator stresses to $27 \%\left(50^{-\frac{1}{3}}\right)$ of the surface values. The effect on the increased effective strain rate is larger than the effect of larger flow parameter. Together, the two effects result in basal stresses that are only $5 \%$ of the measured surface stresses.

Updating the effective strain rate to take account of increased temperature at depth has a positive feed-back effect on the deformation. This can be seen in Figures 6, 7 and 8 for "average longitudinal deviator stresses" and "average shear stress on vertical planes" where temperature curves are included in the calculations. The strong reduction of the surface-measured stresses at the base are here caused by the combination of soft ice and high stress level at the base. At the base, the effective strain rate is totally dominated by horizontal shearing. The horizontal shear stress is only weakly affected by the ice temperature, while the effect on the horizontal velocity is more dramatic (Figs 6, 7 and 8). Keeping the effective strain rate constant at depth will then have only a small effect on the horizontal shear but a greater effect on the estimated horizontal velocity profile at depth. If the 


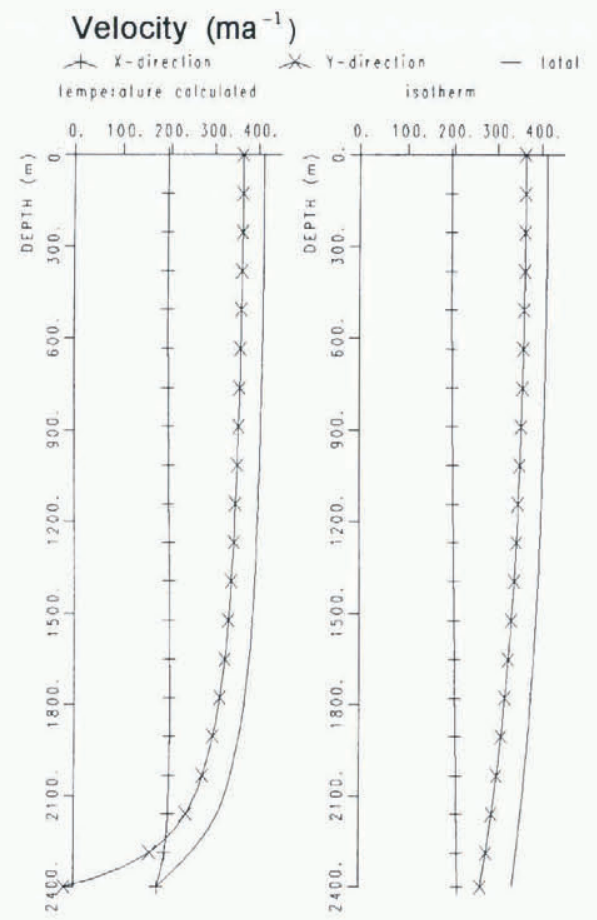

\section{Average longitudinal deviator stresses (kPa)}

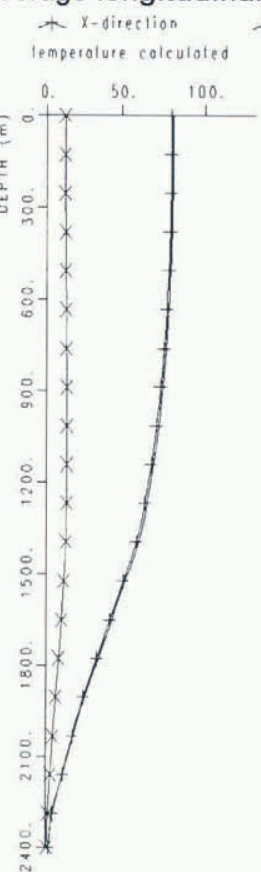

Average shear stress on vertical planes $(\mathrm{kPa})$
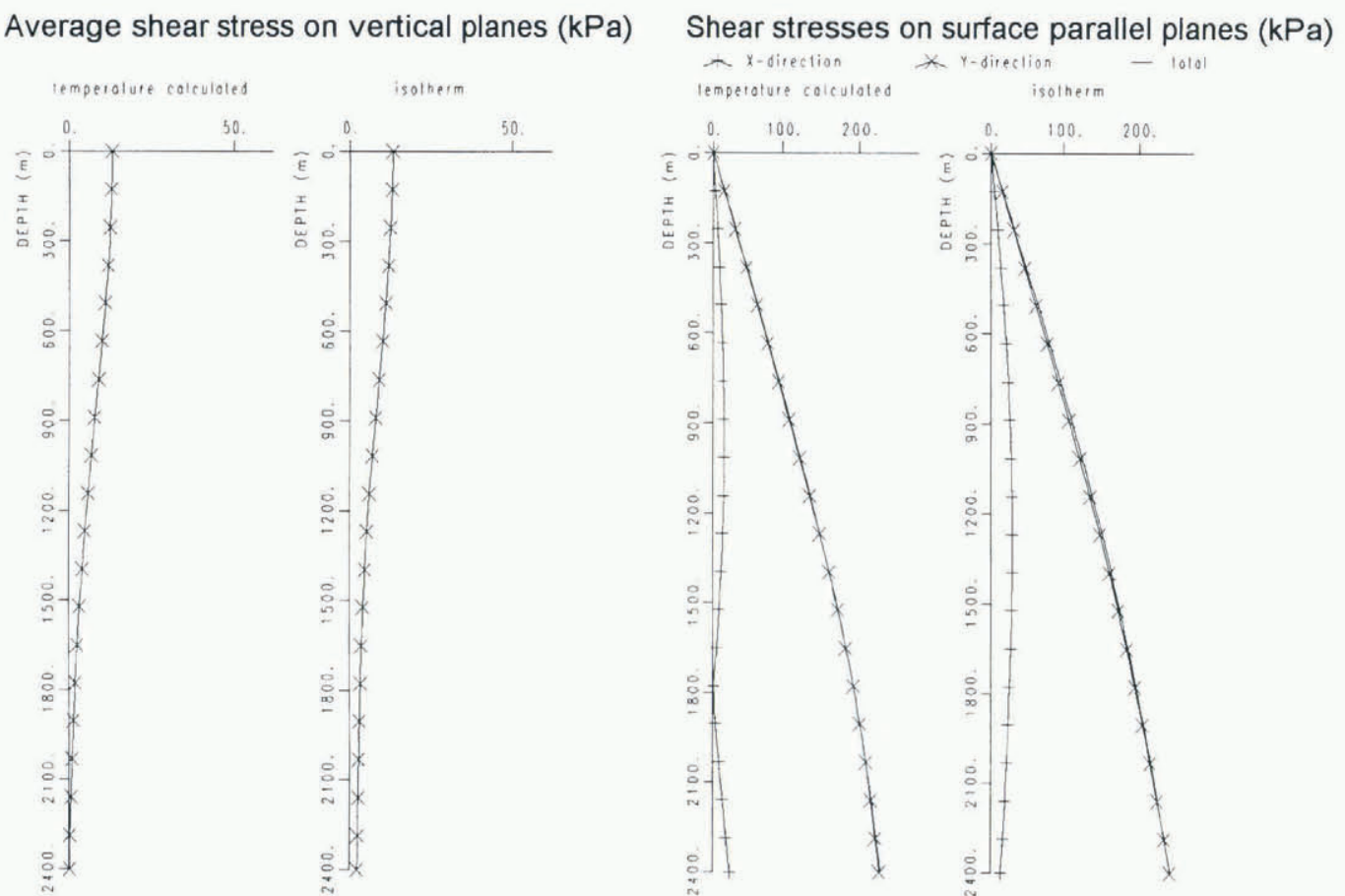

Fig. 7. Strain net No. 2. Velocities and stresses are calculated (1) by using the temperature profile in Figure 5 and (2) by assuming the ice temperature is constant and equal to $-25^{\circ} \mathrm{C}$.

effective strain rate had been kept constant at the surfacemeasured value, the surface-measured stresses would have been reduced to about $27 \%$ of those at the bed.

Force-balance calculations are often made with the effective strain rate measured at the surface kept constant at depth. This makes it possible to integrate directly the force-balance equations to the base. This is equivalent to adjusting the flow parameter to local conditions and solving the force balance with a linear flow law. If the effective strain rate (or effective shear stress) is more or less constant, the depth variation is mainly associated with the temperature-dependence of the flow parameter.
Van der Veen and Whillans (1989b) found a relatively small variation in the effective shear stress with depth and proposed a flow law where the flow parameter included the effective shear stress measured at the surface. They found no significant difference using linear $(n=1)$ and non-linear $(n=3)$ flow laws. In Jutulstraumen, the basal shear stress is about 4 times the basal shear stress at the Byrd Station Strain Network for which Van der Veen and Whillans' calculations were made. The larger basal shear stress makes the choice of exponent in the flow law more important in Jutulstraumen.

To summarize: assumptions about the value of $n$ in 

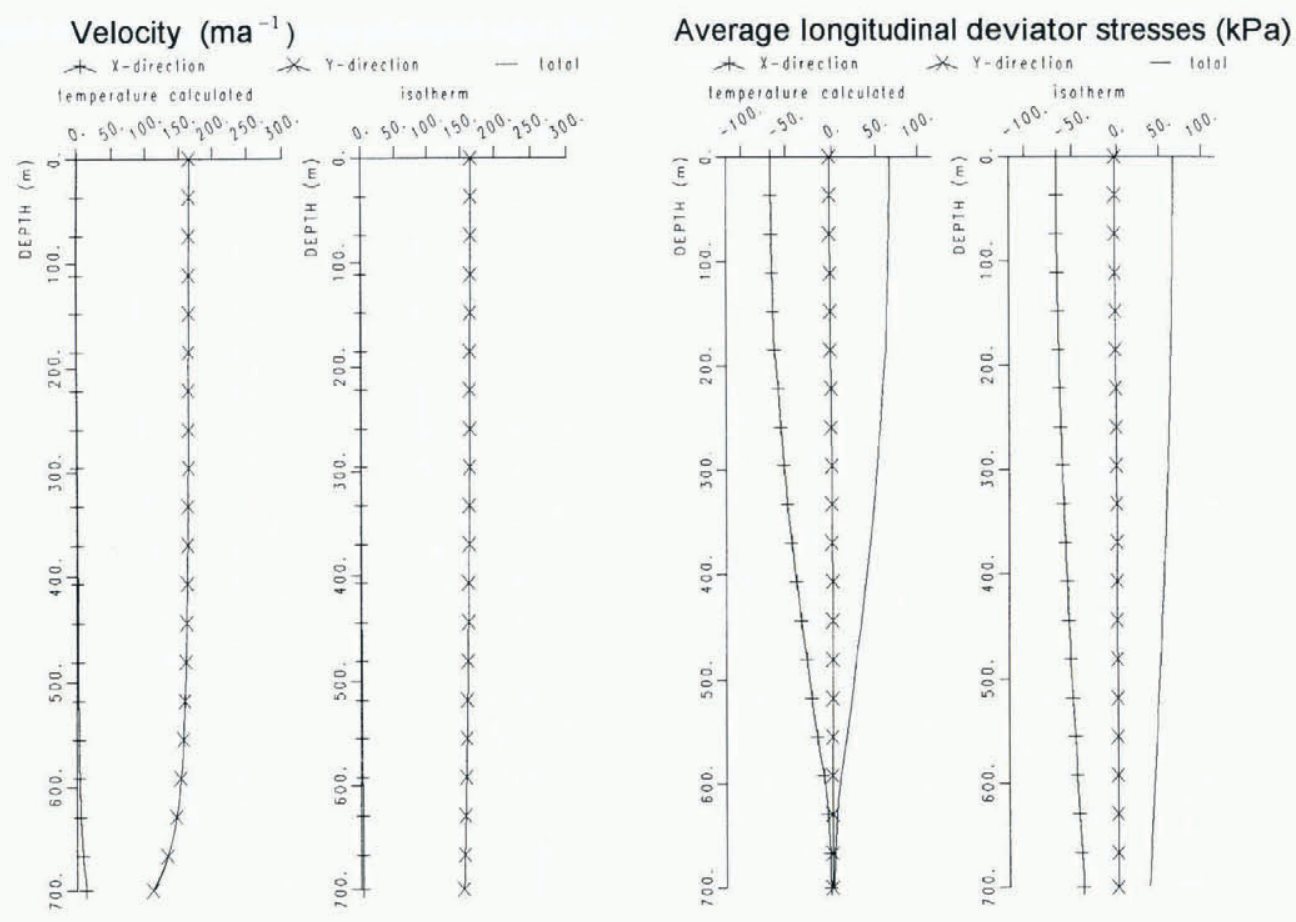

Average shear stress on vertical planes $(\mathrm{kPa})$

Shear stresses on surface parallel planes $(\mathrm{kPa})$
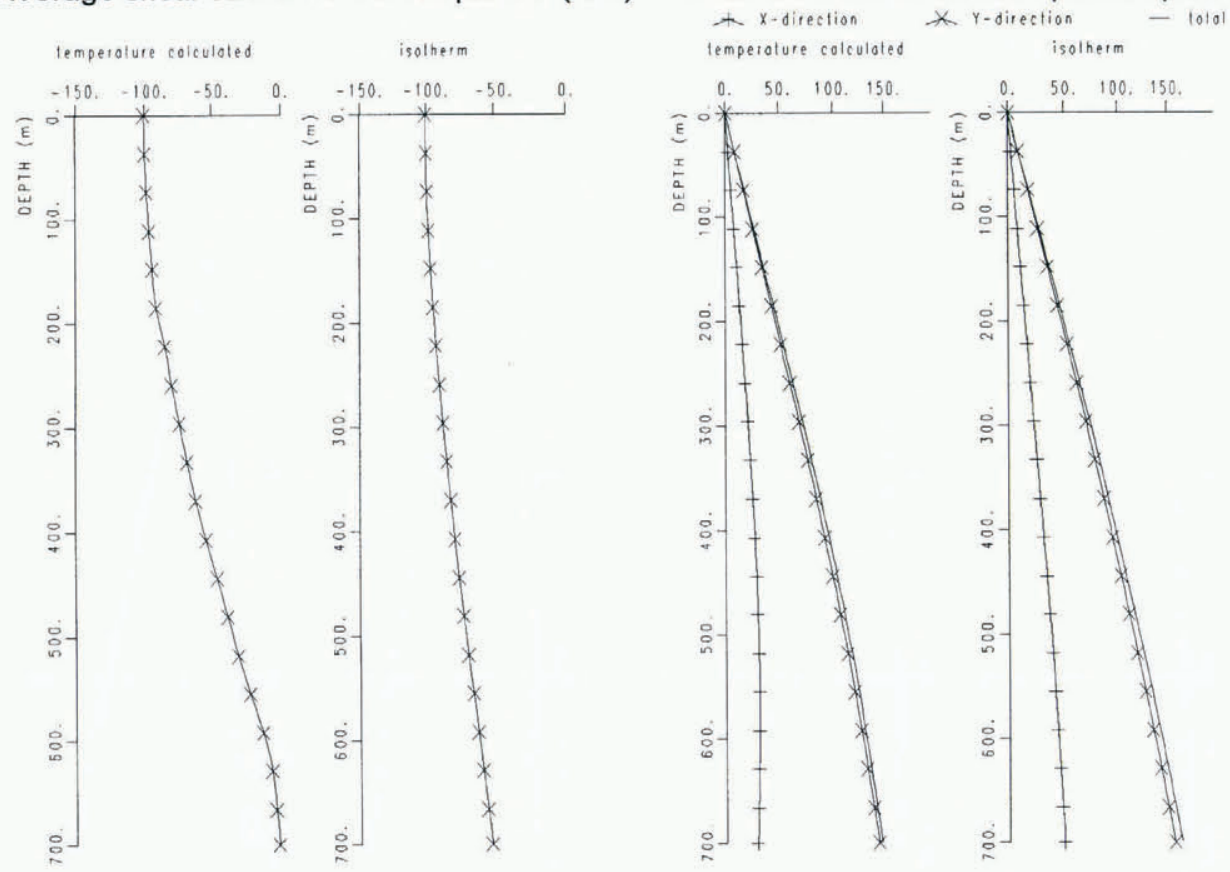

Fig. 8. Strain net No. 3. Velocities and stresses are calculated (1) by using the temperature profile in Figure 5 and (2) by assuming the ice temperature is constant and equal to $-25^{\circ} \mathrm{C}$.

the flow law and how the effective strain rate are incorporated have a greater effect on the results than a few ${ }^{\circ} \mathrm{C}$ error in the calculated temperature profiles.

\section{The surface velocities and stress fields}

The magnitudes of the stresses are related to the velocities and the location in the ice stream. Table 2 shows the values of the interpolated strain rates from measured stake positions and the calculated surface stresses. Figure 4 shows the surface elevation along the profile and, together with the elevation contours in Figures 1 and 2, this helps to clarify the flow patterns. The degree of surface-elevation variation along the profile is surprising considering that the ice thickness is more than $2 \mathrm{~km}$. The flow patterns are consistent with those seen on satellite images.

Net 1

The ice here just passes the last of three nunataks in the Nashorn ridge. Further downstream the surface slope decreases. Thus, there is compression in the flow direction $(\sim y$ direction $)$ and extension in the lateral direction $(\sim x$ direction $)^{-}$(Table 2). The difference in flow direction 
between stakes 30 and 31 (Fig. 2) creates open crevasses and reverses the sign of the vertical shear stress (the side drag) at node 4 .

There is lateral divergence between nets 1 and 2 but a convergence between net 1 and the ice stream from Viddalen (profile 2).

The average vertical shear (the side drag) at the surface is $94.5 \mathrm{kPa}$, which is of the same magnitude as net 3 .

Nel 2

The net lies over the thickest part of the ice stream where the velocities are largest. In the lateral direction $(x$ direction) there is mainly extension. The net lies on a small hill with a depression or channel to the east. Surface velocities from net 2 and eastward indicate lateral convergence into this channel.

Lateral compression might be expected in the shallow depression between nets 1 and 2. However, there is a lateral divergent flow between nets 1 and 2. At the deepest part of the depression there is a large open crevasse transverse to the profile, the only place along the profile with such a large open crevasse. The crevasse belongs to a system that increases in size downstream. Standing at the side of this crevasse, one gets a weak impression of being situated in a trough. Further upstream, K. Melvol (personal communication) has reported a larger trough.

The flow patterns in the profiles indicate that flow west of stake 4 is controlled by the bedrock depression in Viddalen, while ice flow east of stake 4 is controlled by the depression in the middle of profile 1 . The basal relief should then be significant compared to the ice thickness.

The vertical shear stress at net 2 is less than half of that measured at nets 1 and 3 .

\section{Net 3}

The net is situated in an area with a constant surface slope. There is only small variation in the velocities but the $y$ component increases laterally, with a lateral compression due to narrowing of Jutulstraumen as it passes Jutulrøra. The stresses in the $y$ direction are small. The vertical shear stress is $-101 \mathrm{kPa}$ (opposite turning of net 1).

\section{Basal shear stresses and velocities at depth}

The driving stresses at nets 1,2 and 3 are 180, 122 and $111 \mathrm{kPa}$, respectively. The maximum surface slopes are $0.27^{\circ}, 0.32^{\circ}$ and $1.01^{\circ}$, respectively. Errors in the surface slope cause up to $5 \%$ error in the basal stress at net 2 and about $1 \%$ in nets 2 and 3 . Errors which originate from surface slope will be of a similar magnitude for the calculated basal stresses. The calculated basal shear stress at net 1 is $180 \mathrm{kPa}$, i.e. equal to the driving stress. This indicates that the surface stresses balance each other. At net 2 the basal shear stress is $227 \mathrm{kPa}$, twice the driving stress. This is caused by imbalance of surface stresses and a relatively constant stress field in the upper $1500 \mathrm{~m}$. The basal shear stress at net 3 is $146 \mathrm{kPa}, 32 \%$ higher than the driving stress. The difference between the driving stress and the basal shear stress in net 3 is small compared with net 2 , because the stresses are integrated over a smaller depth interval. The ice temperature has a smaller influence on the calculated horizontal shear stresses.
The results from "temperature-calculated" and "isothermal" (Fig. 5) profiles differ by less than 3\% at net 1 where the driving stress is almost equal to the basal shear stress. When the surface stresses become more important, as in nets 2 and 3 , assumed softer ice at depth makes the basal shear stress 13\% less (for both nets 2 and 3 ) than for the case where the ice is treated as being cold and stiff.

Both driving stresses and calculated basal stresses are large, indicating that the base supports the stresses. The basal shear stress in net 2 is $186 \%$ larger than the driving stress. That is mainly due to longitudinal deviator stress in the lateral direction. Net 2 is located on a topographic high that probably overlies a hill in the basal topography. The basal hill supports the stresses from the deeper areas at the sides.

At the ice-stream margins (nets 1 and 3 ), the basal shear stress is lower than in the middle. Side drag is of the same magnitude as basal shear stress and equally important in supporting driving stresses.

Velocities calculated at depth are shown in Figures 6, 7 and 8 . The basal velocities are calculated as 50,171 and $110 \mathrm{~m} \mathrm{a}^{-1}$ for nets 1,2 and 3 , respectively. Velocity at depth is strongly dependent on the ice temperature through its effect on the flow parameter. If the lower 1$2 \%$ of the ice thickness is treated as softer ice by increasing the flow parameter 5 times), the basal velocities become zero at all nets. Thus, sliding velocity cannot be accurately calculated and the only conclusion that can be drawn with confidence is that there is a steep velocity gradient close to the bed.

At net 2 the flow direction at the base is sigificantly different from that at the surface. The $y$ component of the velocity decreases to zero, while the $x$ component remains unchanged. In theory, the force-balance method should accurately predict such changes at depth. The effects of basal topography on flow direction should diminish upward into the ice. The ice at the base will, if possible, divert flow around the obstacle while the ice at the surface is much less affected by bedrock undulations. The flow direction at depth in net 2 turns in the direction of the depression in surface topography shown east of the strain net in Figure 4. The depression is one possible reason for the turning.

In Equations (1), (2) and (3) the gravity components balance the stresses acting on the surface of an element. During integration of the force-balance equations, it is assumed that the measured strain rates and the indirectly measured gravity components (the surface slope) are representative at depth. As a guide, the distances between stakes should equal the ice depth where the deformations need to be studied. The surface slopes and strains could be calculated from increased surface areas during the vertical integration process. However, this would cause loss of resolution at the depth where interesting deformations originate. Looking at Figure 7, a "representative gravity angle" in the $x$ direction at net 2 increases when a larger distance at the surface is used. A larger surface angle causes a larger decrease of the $x$ component at depth but does not necessarily diminish the turn of the flow direction. A larger surface angle in the $x$ direction also influences the velocity field in the $y$ direction, because the effective shear stress at depth increases. Using a 
surface angle in the $x$ direction to calculate zero $x$ velocity at the base gives a high negative velocity in the $y$ direction (the main flow direction)! Thus, the turning cannot be explained from surface-angle input.

The calculations and their sensitivity to surface angles indicate that the $y$ component of the velocity decreases due to internal deformation, while the $x$ component is more stable at depth. The extension in the $x$ direction supports this. The flow direction at the surface is mainly governed by the surface slope. Closer to the bed, bedrock topography will have more influence and changes in the channel geometry introduce longitudinal stresses.

The stress variations over short distances are greater in Jutulstraumen than reported for some other ice streams (Van der Veen and Whillans, 1989b). Jutulstraumen flows within a wide channel in the bedrock and, together with high basal shear stress, this distinguishes such ice streams in East Antarctica from many counterparts in West Antarctica. Even though the ice thickness is more than $2000 \mathrm{~m}$, the surface seems to be influenced by bottom topography. This implies that the velocity close to the bed is significant, regardless of whether there is pure sliding or strong basal deformation. The ice fabric at the base, together with high basal shear stress, probably supports a significant basal movement by deformation. The basal ice is probably highly plastic, so that the strain rates are not well defined as a function of the deviator stress components (Høydal, 1993). If so, then any prediction of velocity changes close to the base can only be hypothetical.

The large gradient in surface velocity from the sides towards the middle of the ice stream do probably also cause basal movements of cold ice around the nunataks. Glacial striations are found on the top of the nunatak Nordre Nashornkalven. They originate probably from the last ice age with a colder climate than today. The ice thickness was then at least $100 \mathrm{~m}$ thicker than today.

\section{Mass flow}

Volume flux through the profiles is determined using depth-varying velocities rather than by assuming plug flow. For each strain-net location, the along-flow velocity is integrated over depth and the ratio of the depthaveraged velocity to the surface velocity is computed as $0.93,0.87$ and 0.96 for nets 1,2 and 3, respectively. Error in the factors is estimated to be less than $10 \%$. The factor is interpolated between strain-net locations and used to compute volume flux through the entire profile. The calculations are shown in Table 1. The volume flux between Jutulrøra and Nashornkalven is $10.78 \mathrm{~km}^{3} \mathrm{a}^{-1}$ and $2.35 \mathrm{~km}^{3} \mathrm{a}^{-1}$ across Viddalen. This gives total $13.13 \mathrm{~km}^{3} \mathrm{a}^{-1}$ outflow at $72^{\circ} 15^{\prime} \mathrm{S}$. The error with respect to the above factors should be less than $1.0 \mathrm{~km}^{3} \mathrm{a}^{-1}$.

Decleir and Van Autenboer (1982) calculated the discharge between Jutulrøra and Nashornkalven as $12.48 \mathrm{~km}^{3} \mathrm{a}^{-1}$ or $1.7 \mathrm{~km}^{3} \mathrm{a}^{-1}$ higher than the present study. They made no attempt to estimate the reduction of horizontal flow with depth. This, together with the higher resolution of surface velocities used in the present study, explains the deviation of their result. The flow out of Viddalen also belongs to the Jutulstraumen drainage system and must be included; when this is added, the present study gives an outflow about $5 \%$ higher than that of Decleir and Van Autenboer (1982). Bentley and Giovinetto (1991) used $16 \mathrm{Gta}^{-1}$ as input (accumulation) and an outflow equal to $11 \mathrm{Gta}^{-1}$ and concluded that Jutulstraumen was not in balance. A large uncertainty is caused by poorly known accumulation and at present it is not possible to say whether the area is truly in or out of balance. Planned Norwegian field work for the coming years includes obtaining better accumulation estimates from shallow snow cores.

The main uncertainty in these calculations is the ice thickness from gravity measurement presented by Gjessing (1972) and reinterpreted by Decleir and Van Autenboer (1982). Minor errors in the depth profiles probably have little influence on the mass-flow shape factors. The flux in Table 1 is then proportional to ice thickness and improved ice-thickness data would reduce the error in the flux estimates.

The lower part of Jutulstraumen (downstream of the profile) is estimated to be $6200 \mathrm{~km}^{2}$ or $5 \%$ of the total catchment area. Assuming that the net balance here is $0.40 \mathrm{maa}^{-1}$ (in w.e.), this gives a volume of $2.5 \mathrm{~km}^{3} \mathrm{a}^{-1}$. The total outflow from Jutulstraumen across the grounding line should then be about $15.6 \mathrm{~km}^{3} \mathrm{a}^{-1}$.

\section{SUMMARY}

Jutulstraumen is an ice stream with a warm base and large basal shear stress. The temperate ice at the base is caused by the movements of the ice stream itself. Large basal shear stresses lead to high effective strain rates. It is important that the force-balance calculations are performed such that the effective strain rate is calculated progressively downwards. Assumptions about the flow law and temperature are not important in computing the basal shear stress. However, these assumptions are important in relation to the depth variation of the horizontal velocity. The large basal shear stress and warm basal temperatures computed here imply that basal sliding occurs. Calculated values of basal sliding range from 50 to $171 \mathrm{~m} \mathrm{a}^{-1}$.

The basal topography controls the flow direction and this indicates that the basal relief is significant compared to the ice thickness. There is good agreement between measured deformations and observed flow patterns and topography.

The discharge between Istind and Nordre Nashornkalven is $2.35 \mathrm{~km}^{3} \mathrm{a}^{-1}$. Between Nordre Nashornkalven and Jutulrora the discharge is $10.78 \mathrm{~km}^{3} \mathrm{a}^{-1}$. The total discharge through the profiles is $13.1 \mathrm{~km}^{3} \mathrm{a}^{-1}$.

\section{ACKNOWLEDGEMENTS}

I thank J. Kohler, I. Whillans and O. Orheim for helpful comments during the writing process and especially I thank C. Hulbe for suggesting improvements on the structure of the paper and improving the clarity of the writing.

I also thank the members of NARE 92/93 who participated in the field work. They were B. Barstad, T. Eiken, J. O. Hagen, B. Lytskjold, K. Melvold, H. H. 
Thomsen and J.G. Winther. This paper is Norsk Polarinstitutt Contribution No. 310.

\section{REFERENCES}

Bentley, C. R. and M. B. Giovinetto. 1991. Mass balance of Antarctica and sea level change. In Weller, G., C. L. Wilson and B.A.B. Severin, eds. International Conference on the Role of the Polar Regions in Global Change. Proceedings of a conference held June 11-15, 1990 at the University of Alaska Fairbanks. Volume II. Fairbanks, AK, University of Alaska Fairbanks. Geophysical Institute and Center for Global Change and Arctic System Research, 481-488.

Decleir, H. and T. van Autenboer. 1982. Gravity and magnetic anomalies across Jutulstraumen, a major geologic feature in western Dronning Maud land. In Craddock, C., ed. Antarctic geoscience. Symposium on Antarctic Geology and Geophysics, Madison, Wisconsin, U.S.A., August 22-27, 1977. Madison, WI, University of Wisconsin Press, 941-948.

Eiken, T. In press. Report of the Norwegian Antarctic Expedition, 92 93. In Meddelser fra Norsk Polarinstitutt, Nr 125.

Gjessing, Y. T. 1972. Mass transport of Jutulstraumen ice stream in Dronning Maud Land. Nor. Polarinst. Arbok 1970, 227-232.

Hooke, R. LeB. 1981. Flow law for polycrystalline ice in glaciers: comparison of theoretical predictions, laboratory data, and field measurements. Rev. Geophys. Space Phys., 19 4), 664672.

Hoydal, O. A. 1993. Plastic modelling of glaciers and outlets. In Peltier, W. R., ed. Ice in the climate system. Berlin, etc., Springer-Verlag, 55-65.
NATO ASI Series I: Global Environmental Change 12.

Høydal, O. A. In press. Report of the Norwegian Antarctic Expedition, 92 93. In Meddelser fra Norsk Polarinstitutt, Nr 125.

Melvold, K. and J.O. Hagen. In press. Report of the Norwegian Antarctic Expedition, 92-93. In Meddelser fra Norsk Polarinstitutt, $\mathrm{Nr}$ 125.

Paterson, W. S. B. 1981. The physics of glaciers. Second edition. Oxford, etc, Pergamon Press.

Paterson, W. S. B. and W. F. Budd. 1982. Flow parameters for ice sheet modelling. Cold Reg. Sci. Technol., 6(2), 175-177.

Robin, G.de Q. 1955. Ice movement and temperature distribution in glaciers and ice sheets. J. Glaciol., 2 (18), 523-532.

Schytt, V. 1958. The inner structure of the ice shelf at Maudheim as shown by core drilling. Norwegian-British-Swedish Antarctic Expedition, 1949-52. Sci. Results IV, Glaciology II, C, 113-152.

Sclater, J. G., C. Jaupart and D. Galson. 1980. The heat flow through oceanic and continental crust and the heat loss of the Earth. Rev. Geophys. Space Phys., 18, 289-311.

Van Autenboer, T. and H. Decleir, 1978. Glacier discharge in the SorRondane, a contribution to the mass balance of Dronning Maud Land, Antarctica. Z. Gletscherkd. Glazialgeol., 14(1), 1-16.

Van der Veen, C.J. 1989. A numerical scheme for calculating stresses and strain rates in glaciers. Math. Geol., 21 (3), 363-377.

Van der Veen, C. J. and I. M. Whillans. 1989a. Force budget: I. Theory and numerical methods. J. Glaciol., 35(119), 53-60.

Van der Veen, C.J. and I. M. Whillans. 1989b. Force budget: II. Application to two-dimensional flow along Byrd Station Strain Network, Antarctica. 7. Glaciol., 35 (119), 61-67.

Vinje, T. E. 1977. Drift av Trolltunga i Weddellhavet. Norsk Polarinst. Arbok 1975, 213.

MS received 9 November 1994 and accepted in revised form 20 January 1996 